\title{
Molecular Docking-Based Design and Development of a Highly Selective Probe Substrate for UDP-glucuronosyltransferase 1 A10
}

Risto O. Juvonen, ${ }^{* \dagger \oplus ~ S a n n a ~ R a u h a m a ̈ k i, ~}{ }^{\ddagger}$ Sami Kortet, ${ }^{\ddagger}$, Sanna Niinivehmas, ${ }^{\ddagger}$ Johanna Troberg, Aleksanteri Petsalo, ${ }^{\dagger}$ Juhani Huuskonen, ${ }^{\S}$ Hannu Raunio, ${ }^{\dagger}$ Moshe Finel, ${ }^{\| \odot}$ and Olli T. Pentikäinen ${ }^{*},+, \perp_{\odot}$

${ }^{\dagger}$ School of Pharmacy, Faculty of Health Sciences, University of Eastern Finland, Box 1627, FI-70211 Kuopio, Finland

${ }^{\ddagger}$ Department of Biological and Environmental Science and ${ }^{\S}$ Department of Chemistry, University of Jyvaskyla, P.O. Box 35, FI-40014 Jyvaskyla, Finland

"Division of Pharmaceutical Chemistry and Technology, Faculty of Pharmacy, University of Helsinki, P.O. Box 56, FI-00014 Helsinki, Finland

${ }^{\perp}$ Institute of Biomedicine, Faculty of Medicine, University of Turku, FI-20014 Turku, Finland

Supporting Information

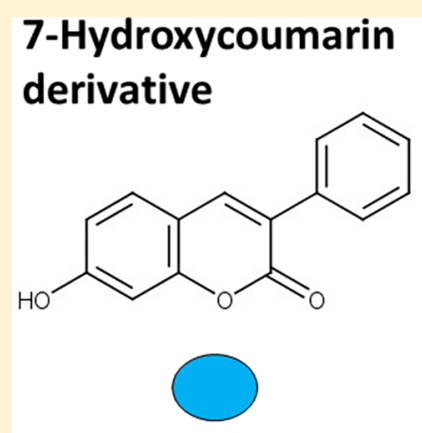

Fluorescent

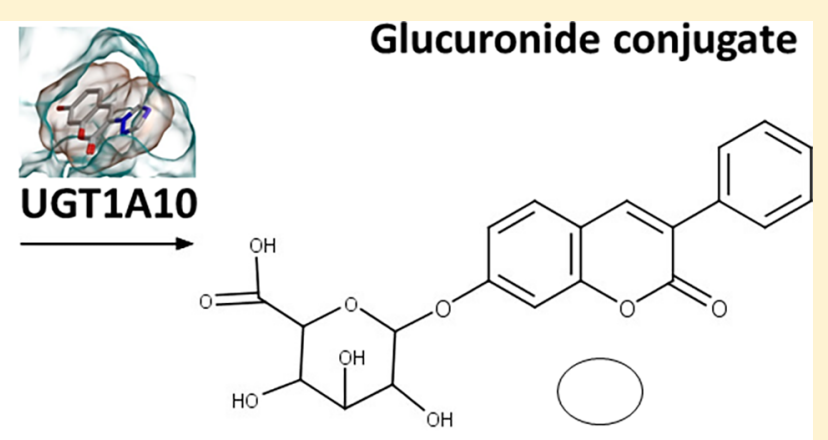

Non-fluorescent

ABSTRACT: Intestinal and hepatic glucuronidation by the UDP-glucuronosyltransferases (UGTs) greatly affect the bioavailability of phenolic compounds. UGT1A10 catalyzes glucuronidation reactions in the intestine, but not in the liver. Here, our aim was to develop selective, fluorescent substrates to easily elucidate UGT1A10 function. To this end, homology models were constructed and used to design new substrates, and subsequently, six novel C3-substituted (4-fluorophenyl, 4hydroxyphenyl, 4-methoxyphenyl, 4-(dimethylamino)phenyl, 4-methylphenyl, or triazole) 7-hydroxycoumarin derivatives were synthesized from inexpensive starting materials. All tested compounds could be glucuronidated to nonfluorescent glucuronides by UGT1A10, four of them highly selectively by this enzyme. A new UGT1A10 mutant, 1A10-H210M, was prepared on the basis of the newly constructed model. Glucuronidation kinetics of the new compounds, in both wild-type and mutant UGT1A10 enzymes, revealed variable effects of the mutation. All six new C3-substituted 7-hydroxycoumarins were glucuronidated faster by human intestine than by liver microsomes, supporting the results obtained with recombinant UGTs. The most selective 4(dimethylamino)phenyl and triazole C3-substituted 7-hydroxycoumarins could be very useful substrates in studying the function and expression of the human UGT1A10.

KEYWORDS: 7-hydroxycoumarin derivative, UDP-glucuronosyltransferase, in silico, fluorescence, drug metabolism

\section{INTRODUCTION}

The extents of absorption and first-pass metabolism in the intestine and liver strongly affect the bioavailability of drugs and other orally ingested xenobiotic compounds. ${ }^{1,2}$ Although hepatic metabolism is the major determinant of first-pass metabolism for most drugs, intestinal metabolism is critical for the bioavailability of certain compounds, particularly those that could be directly conjugated, like phenols and flavonoids. ${ }^{3-5}$ Such xenobiotics typically contain a nucleophilic functional group, usually a hydroxyl group, that can accept an endogenous conjugating moiety, particularly glucuronic acid or sulfone.
More rarely, the conjugating group is methyl, acetyl, or amino acid. $^{6}$

The UDP-glucuronosyltransferase enzymes (UGTs, EC 2.4.1.17) catalyze about $35 \%$ of the drug conjugation reactions and are abundantly expressed among the intestinal conjugating enzymes. ${ }^{4,5,7}$ They catalyze transfer of the glucuronic acid moiety from UDP-glucuronic acid cofactor onto hydroxyl,

Received: October 5, 2017

Revised: January 18, 2018

Accepted: February 8, 2018

Published: February 8, 2018 


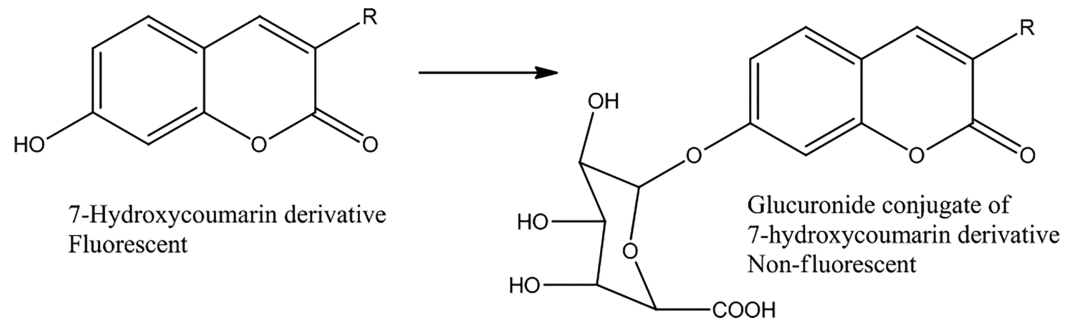

Figure 1. Glucuronidation of 7-hydroxycoumarin derivatives. Fluorescent 3-substituted 7-hydroxycoumarins are glucuronidated to nonfluorescent glucuronide conjugates by UGT enzymes. The decrease in fluorescence can be measured conveniently in different kinds of experimental setups.

amine, carboxylic acid, thiol, or thioacid groups of the aglycone substrates, reactions that are commonly called glucuronidation. ${ }^{8}$ There is a significant difference in the expression profile of individual UGTs between the intestine and liver. ${ }^{9-11}$ While about 10 different UGTs are abundantly expressed in the liver, only UGT1A1, UGT1A10, UGT2B7, and UGT2B17 are expressed in the small intestine to significant amounts at the protein level. ${ }^{10,12-14}$ Unfortunately, the high activity and importance of the intestinal UGT1A10 was (and still is) often underestimated due to common use of poorly active commercial UGT1A10. ${ }^{13}$

UGT1A10 glucuronidates many drugs and xenobiotics. $^{13,15-17}$ Glucuronidation of estriol at the $3-\mathrm{OH}$ and of estrone could be used as a selective reaction for UGT1A10, but the measurements require chromatographic separation of the resulting glucuronide from the substrate. ${ }^{6,18}$ Likewise, dopamine is a UGT1A10-selective substrate, but its low affinity $^{19}$ has limited its use to qualitative measurements only. ${ }^{14}$ Accordingly, availability of more convenient marker substrates for UGT1A10 would foster evaluation of glucuronidation reactions, particularly if the assays were easy and fast to perform.

The interactions between substrates and xenobiotic metabolizing enzymes are increasingly being studied by in silico modeling. ${ }^{20-23}$ Currently, the lack of crystal structures of the $\mathrm{N}$-terminal domain of any mammalian UGT impedes the structure-activity relationship and mechanistic studies. UDPglucuronic acid binds at the C-terminal domain, which is highly homologous among different UGTs and evolutionary conserved. The structure of the latter domain has been solved by X-ray crystallography. ${ }^{24}$ However, that available crystal structure does not provide sufficient data to predict binding of acceptor substrates, e.g., a drug molecule, as substrates bind to the N-terminal domain, which is more variable than the $\mathrm{C}$ terminal domain among UGT enzymes. In silico models for this domain were constructed previously, ${ }^{20,21}$ but we need better ones in order to analyze substrate-enzyme interactions in UGTs at the atomic level.

The hydroxyl group at C7 on the coumarin scaffold renders the compound fluorescent and glucuronidation of this hydroxyl abolishes the fluorescence (Figure 1). ${ }^{25}$ Substituents at positions such as $\mathrm{C} 3$ or $\mathrm{C} 4$ of the coumarin do not quench the 7-hydroxycoumarin derivatives' fluorescence but modify its intensity, depending on the substituent's chemical nature. The 7-hydroxyl group on coumarin is also a good functional group for glucuronidation by many UGTs. Therefore, fluorescent 7hydroxycoumarin derivatives provide an opportunity to design novel fluorescent substrates for UGTs using molecular modeling as the starting point.

In this study, we first constructed homology models for all the human UGT enzymes of subfamily $1 \mathrm{~A}$ and used them to design fluorescent 7-hydroxycoumarin derivatives in silico. We then synthesized six compounds and developed a convenient multiwell plate assay protocol, based on fluorescence decrease, to test their glucuronidation rate. The results led to the identification of several 3-substituted 7-hydroxycoumarins as selective substrates for the human UGT1A10. A UGT1A10 mutant was prepared based on the model and as a test for it. Subsequently, glucuronidation kinetic analyses of the 3substituted 7-hydroxycoumarins, by wild-type and mutant UGT1A10, were carried out using the same multiwell plate assay protocol.

\section{EXPERIMENTAL SECTION}

Materials. Alamethicin, trichloroacetic acid, UDPGA sodium salt, 7-hydroxycoumarin (99\%), 7-hydroxy-(4trifluoromethyl)coumarin (99\%), and bovine serum albumin were from Sigma-Aldrich (Mannheim, Germany). Formic acid (99\%) and $\mathrm{MgCl}_{2}$ were from Riedel-de Haen (Vantaa, Finland). Acetonitrile (Ultra gradient HPLC grade), methanol (HPLC gradient grade), and glycine were from J.T. Baker (Deventer, The Netherlands). Ethanol ( $\geq 99.5 \%$, Etax Aa) was from Altia (Helsinki, Finland). Water was deionized by Milli-Q gradient A10.

Methods. Modeling. To enable structure-based design of UGT1A10 selective substrates, all nine UGT1A-enzymes were modeled. Sequences of human UGT1A enzymes were gathered from the UniProt Knowledgebase at www.uniprot.org (UniProt Consortium, 2015). The accession codes for the retrieved UGT1As were: Q9HAW8 (1A10), O60656 (1A9), Q9HAW9 (1A8), Q9HAW7 (1A7), P19224 (1A6), P35504 (1A5), P22310 (1A4), P35503 (1A3), and P22039 (1A1). To identify template protein structures for homology modeling purposes, the retrieved UGT sequences were used in blast searches against the protein data bank (PDB) structures. Based on the results of these searches, structures $2 \mathrm{O} 6 \mathrm{~L},{ }^{24} 3 \mathrm{HBF},{ }^{26} 3 \mathrm{WC} 4,{ }^{27}$ and $2 \mathrm{C}^{2} \mathrm{Z}^{28}$ were selected as templates for homology modeling. The sequence alignment for the modeling was produced in two steps. First a protein structure-based sequence alignment was derived for the selected four protein structures by using Vertaa in BODIL ${ }^{29}$ and the $2 \mathrm{C} 1 \mathrm{Z}$-structure as a template, since it gave the best match for UGT1A10 and contained both the N- and C-termini. In the second step the above listed nine UGT1A sequences were aligned, using BODIL, against the structural alignment, using STRMAT110 matrix $^{30}$ with 40 as the gap penalty. The alignment was adjusted for occasional variations in sequence length and used to create models for each UGT1A as well as in model construction that was performed using Modeler version 9.15..$^{31}$

Molecular Docking. The ligands that were selected for docking studies were prepared by using LigPrep (version 3.3, Schrödinger, LLC, New York, 2015). The shapes and 
Scheme 1. General Procedure for the Synthesis of Coumarin Derivatives

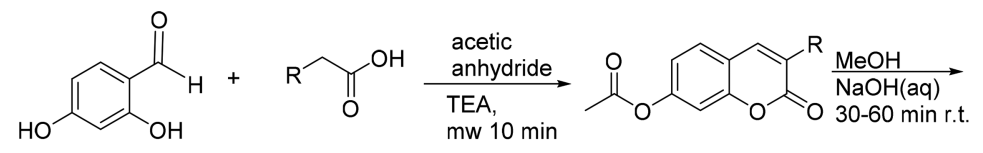
mw 10

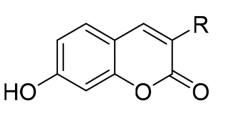

$1 \mathrm{R}=4$-fluorophenyl

$2 R=4$-hydroxyphenyl

$3 R=4$-(dimethylamino)pheny

$4 \mathrm{R}=\mathrm{p}$-tolyl electrostatic properties of the substrate binding sites of modeling-produced UGT1A enzymes were analyzed with Panther, $^{32}$ and molecular docking was performed with PLANTS. $^{33}$

Synthesis. All the synthesis reactions were carried out using commercial materials and reagents without further purification, unless otherwise noted. Reaction mixtures were heated using the CEM Discovery microwave apparatus. All reactions were monitored by thin-layer chromatography (TLC) on silica gel plates. ${ }^{1} \mathrm{H}$ NMR and ${ }^{13} \mathrm{C}$ NMR data were recorded on a Bruker Avance $400 \mathrm{MHz}$ spectrometer or Bruker Avance III $300 \mathrm{MHz}$ spectrometer. Chemical shifts are expressed in parts per million values (ppm) and are designated as s (singlet), br s (broad singlet), d (doublet), dd (double douplet), t (triplet). Coupling constants $(J)$ are expressed as values in hertz $(\mathrm{Hz})$. The mass spectra were recorded using Micromass LCT ESI-TOF equipment. Elemental analyses were done with Elementar Vario EL III elemental analyzer. All compounds tested present more than $95 \%$ purity.

General Procedure for the Synthesis of Coumarin Derivatives. The coumarin derivatives $\mathbf{1 - 6}$ were synthesized using the Perkin-Oglialor condensation reaction (Scheme 1). The method was developed from the previously published procedures and transferred to a microwave reactor. ${ }^{34}$

Typical procedure: A mixture of salicylaldehyde derivative (2 $\mathrm{mmol})$ and phenyl acetic acid derivative $(2.1 \mathrm{mmol})$, acetic acid anhydride $(0.6 \mathrm{~mL})$, and triethylamine $(0.36 \mathrm{~mL})$ was placed in a microwave reactor tube and heated at $100-170{ }^{\circ} \mathrm{C}$ in the microwave apparatus for 10-20 min. After cooling, $2 \mathrm{~mL}$ of $10 \% \mathrm{NaHCO}_{3}$ solution was added, and the precipitate was filtered, dried, and recrystallized from $\mathrm{EtOH} / \mathrm{H}_{2} \mathrm{O}$ or acetone/ $\mathrm{H}_{2} \mathrm{O}$ mixture. The acetyl group $(\mathrm{s})$ were removed by treating the compound with $\mathrm{MeOH} / \mathrm{NaOH}(\mathrm{aq})$ solution for 30-60 min at rt. The solution was acidified with $\mathrm{HCl}(\mathrm{aq})$, and the precipitate was filtered and recrystallized if needed. Experimental data for 7-acetoxy-3-(4-fluorophenyl)-2H-chromen2one, 7-hydroxy-3-(4-fluorophenyl)-2H-chromen-2-one (1), 7-acetoxy-3-(4-acetoxyphenyl)-2H-chromen-2one, 7-hydroxy3-(4-hydroxyphenyl)-2H-chromen-2one (2), and 7-acetoxy-3(4-methoxyphenyl)coumarin, 7-hydroxy-3-(4-methoxyphenyl)coumarin (3) were already published elsewhere. ${ }^{34}$

7-Hydroxy-3-(4-(dimethylamino)phenyl)-2H-chromen-2one (4). ${ }^{35}$ In the first step, 7-acetoxy-3-(4-(dimethylamino)phenyl)-2H-chromen-2one was obtained. Yield: $70 \% .{ }^{1} \mathrm{H}$ NMR $\left(400 \mathrm{MHz}, \mathrm{DMSO}-d_{6}\right) \delta: 2.31\left(\mathrm{~s}, 3 \mathrm{H}, \mathrm{CH}_{3} \mathrm{CO}\right), 2.95$ (s, 6H, $\left.\left(\mathrm{CH}_{3}\right)_{2} \mathrm{~N}-\right), 6.77\left(\mathrm{~d}, J^{3}=9.0 \mathrm{~Hz}, 2 \mathrm{H}, \mathrm{H}-2^{\prime}, \mathrm{H}-6^{\prime}\right), 7.14\left(\mathrm{dd}, J^{3}\right.$ $\left.=8.4 \mathrm{~Hz}, J^{4}=2.2 \mathrm{~Hz}, 1 \mathrm{H}, \mathrm{H}-5\right), 7.26\left(\mathrm{~d}, J^{4}=2.2 \mathrm{~Hz}, 1 \mathrm{H}, \mathrm{H}-8\right)$, $7.63\left(\mathrm{~d}, J^{3}=9.0 \mathrm{~Hz}, 2 \mathrm{H}, \mathrm{H}-3^{\prime}, \mathrm{H}-5^{\prime}\right) 7.76\left(\mathrm{~d}, J^{3}=8.5 \mathrm{~Hz}, 1 \mathrm{H}\right.$, H-5), 8.11 (s, 1H, H-4). ${ }^{13} \mathrm{C}$ NMR (100.6 MHz, DMSO-d $\left.{ }_{6}\right) \delta$ : $20.85,39.84,109.44,111.58,117.76,118.57,121.57,126.00$, 128.82 , 129.11, 136.46, 150.45, 151.90, 152.77, 159.74, 168.85 . In the second step, 7-hydroxy-3-(4-(dimethylamino)phenyl)$2 \mathrm{H}$-chromen-2one (4) was obtained. Yield: $85 \%$ yellow solid. ${ }^{1} \mathrm{H}$ NMR (400 MHz, DMSO- $\left.d_{6}\right) \delta: 2.94\left(\mathrm{~s}, 6 \mathrm{H},\left(\mathrm{CH}_{3}\right)_{2} \mathrm{~N}-\right.$ ), $6.72\left(\mathrm{~d}, J^{4}=2.3 \mathrm{~Hz}, 1 \mathrm{H}, \mathrm{H}-8\right), 6.75\left(\mathrm{~d}, J^{3}=9.0 \mathrm{~Hz}, 2 \mathrm{H}, \mathrm{H}-2^{\prime}\right.$, H-6'), 6.79 (dd, $\left.J^{3}=8.4 \mathrm{~Hz}, J^{4}=2.3 \mathrm{~Hz}, 1 \mathrm{H}, \mathrm{H}-5\right)$ ), $7.55\left(\mathrm{~d}, J^{3}\right.$ $=8.5 \mathrm{~Hz}, 1 \mathrm{H}, \mathrm{H}-5), 7.58\left(\mathrm{~d}, J^{3}=9.0 \mathrm{~Hz}, 2 \mathrm{H}, \mathrm{H}-3^{\prime}, \mathrm{H}-5^{\prime}\right), 7.99$ (s, 1H, H-4). ${ }^{13} \mathrm{C}$ NMR (100.6 MHz, DMSO-d $\left.d_{6}\right) \delta: 39.92$, $101.59,112.33,113.16,122.30,122.32,129.34,137.83,150.07$, 154.27, 160.30, 160.41. ESI-MS: $m / z$ (rel abund) $304[\mathrm{M}+$ $\mathrm{Na}^{+}$. Anal. Calcd for $\mathrm{C}_{17} \mathrm{H}_{15} \mathrm{~N}_{1} \mathrm{O}_{3}:$ C, 72.58; H, 5.37; N, 4.98. Found: C, 72.45; H, 5.40; N, 5.15.

7-Hydroxy-3-(p-tolyl)-2H-chromen-2-one (5). ${ }^{36}$ In the first step, 7-acetoxy-3-( $p$-tolyl)-2H-chromen-2one was obtained. Yield: 70\%. ${ }^{1} \mathrm{H}-\mathrm{NMR}\left(300 \mathrm{MHz}, \mathrm{d}^{6}\right.$-DMSO) $\delta: 2.34(\mathrm{~s}, 3 \mathrm{H}$, $\left.\mathrm{CH}_{3}-\mathrm{Ph}\right), 6.75\left(\mathrm{~d}, J^{4}=2.2 \mathrm{~Hz}, 1 \mathrm{H}, \mathrm{H}-8\right), 6.81\left(\mathrm{dd}, J^{3}=8.5 \mathrm{~Hz}\right.$, $\left.J^{4}=2.2 \mathrm{~Hz}, 1 \mathrm{H}, \mathrm{H}-6\right), 7.23\left(\mathrm{~d}, J^{3}=8.0 \mathrm{~Hz}, 2 \mathrm{H}, \mathrm{H}-2^{\prime}, \mathrm{H}-6^{\prime}\right)$, $7.58\left(\mathrm{~d}, J^{3}=8.5 \mathrm{~Hz}, 1 \mathrm{H}, \mathrm{H}-5\right), 7.59\left(\mathrm{~d}, J^{3}=8.1 \mathrm{~Hz}, 2 \mathrm{H}, \mathrm{H}-3^{\prime}\right.$, $\mathrm{H}^{\prime}$ ), 8.10 (s, 1H, H-4), 10.54 (s, 1H, Ph-OH). $\delta: 2.32$ (s, 3H, $\mathrm{CH}_{3} \mathrm{CO}$ ), $2.35\left(\mathrm{~s}, 3 \mathrm{H}, \mathrm{CH}_{3}-\mathrm{Ph}\right), 7.17\left(\mathrm{dd}, \mathrm{J}^{3}=8.4 \mathrm{~Hz}, \mathrm{~J}^{4}=2.2\right.$ $\mathrm{Hz} 1 \mathrm{H}, \mathrm{H}-6), 7.27$ (d, $\left.J^{3}=8.0 \mathrm{~Hz}, 2 \mathrm{H}, \mathrm{H}-2^{\prime}, \mathrm{H}-6^{\prime}\right), 7.29$ (d, $J^{4}$ $=2.2 \mathrm{~Hz}, 1 \mathrm{H}, \mathrm{H}-8), 7.63\left(\mathrm{~d}, J^{3}=8.2 \mathrm{~Hz}, 2 \mathrm{H}, \mathrm{H}-3^{\prime}, \mathrm{H}-5^{\prime}\right) 7.80$ $\left(\mathrm{d}, J^{3}=8.5 \mathrm{~Hz}, 1 \mathrm{H}, \mathrm{H}-5\right), 8.21$ (s, $\left.1 \mathrm{H}, \mathrm{H}-4\right) .{ }^{13} \mathrm{C}$ NMR (100.6 $\left.\mathrm{MHz}, \mathrm{DMSO}-d_{6}\right) \delta: 20.77,20.82,109.56,117.37,118.66$, $125.99,128.25,128.76,129.30,131.60,138.09,139.37,152.51$, 153.28, 159.47, 168.74.

In the second step, 7-hydroxy-3-( $p$-tolyl)-2H-chromen-2one (5) was obtained. Yield: $85 \%$ brownish solid. ${ }^{1} \mathrm{H}$ NMR (300 $\left.\mathrm{MHz}, \mathrm{DMSO}-d_{6}\right) \delta .{ }^{13} \mathrm{C}$ NMR $\left(75 \mathrm{MHz}, \mathrm{DMSO}-d_{6}\right) \delta: 20.74$, $101.65,112.01,113.30,122.07,128.04,128.69,129.80,132.14$, $137.37,140.38,154.77,160.05,161.05$. ESI-MS: $m / z$ (rel abund) $275\left[\mathrm{M}+\mathrm{Na}^{+}\right]$. Anal. Calcd for $\mathrm{C}_{16} \mathrm{H}_{12} \mathrm{O}_{3}: \mathrm{C}, 76.18 ; \mathrm{H}$, 4.79. Found: C, 75.95; $\mathrm{H}, 4.83$.

7-Hydroxy-3-(1H-1,2,4-triazol-1-yl)-2H-chromen-2-one (6). In the first step, 2-oxo-3-(1H-1,2,4-triazol-1-yl)-2H-chromen-7yl acetate was obtained. Yield: $65 \%$ slightly brown solid. ${ }^{1} \mathrm{H}$ NMR (400 MHz, DMSO-d $d_{6} \delta: 2.33$ (s, 3H, $\mathrm{CH}_{3}-\mathrm{CO}$ ), 7.27 $\left(\mathrm{dd}, J^{3}=8.5 \mathrm{~Hz}, J^{4}=2.2 \mathrm{~Hz}, 1 \mathrm{H}, \mathrm{H}-6\right), 7.44\left(\mathrm{~d}, J^{4}=2.2 \mathrm{~Hz} 1 \mathrm{H}\right.$, H-8), $7.98\left(\mathrm{~d}, \mathrm{~J}^{3}=8.5 \mathrm{~Hz}, 1 \mathrm{H}, \mathrm{H}-5\right), 8.33$ (s, 1H, H-3'), 8.61 (s, $1 \mathrm{H}, \mathrm{H}-4), 9.20\left(\mathrm{~s}, 1 \mathrm{H}, \mathrm{H}-5^{\prime}\right) .{ }^{13} \mathrm{C}$ NMR $(100.6 \mathrm{MHz}, \mathrm{DMSO}-$ $\left.d_{6}\right) \delta: 20.87,110.02,116.19,119.50,123.04,130.10,131.81$, $144.40,152.06,152.21,153.12,155.73,168.76$. FT-IR (KBr, $\left.\mathrm{cm}^{-1}\right): 3416,1723,1617,1208,1129 . \mathrm{Mp}: 190-192{ }^{\circ} \mathrm{C}$. ESIMS: $m / z$ (rel abund): calcd for $\left[\mathrm{M}+\mathrm{Na}^{+}\right] 294.0485$, measured 294.0499, $\Delta=-1.4 \mathrm{mDa}$.

In the second step, the acetyl group was removed by treating the above-mentioned compound with $\mathrm{MeOH} / \mathrm{K}_{2} \mathrm{CO}_{3}$ solution. Yield: $92 \%$ slightly brown solid. ${ }^{1} \mathrm{H}$ NMR (400 MHz, DMSO$\left.d_{6}\right) \delta: 6.85\left(\mathrm{~d}, J^{4}=2.3 \mathrm{~Hz}, 1 \mathrm{H}, \mathrm{H}-8\right), 6.90\left(\mathrm{dd}, J^{3}=8.5 \mathrm{~Hz}, J^{4}=\right.$ $2.3 \mathrm{~Hz}, 1 \mathrm{H}, \mathrm{H}-6), 7.74\left(\mathrm{~d}, J^{3}=8.6 \mathrm{~Hz}, 1 \mathrm{H}, \mathrm{H}-5\right), 8.27(\mathrm{~s}, 1 \mathrm{H}$, H-3'), 8.49 (s, 1H, H-4), 9.10 (s, 1H, H-5'), 10.83 (br s, $1 \mathrm{H}$, $\mathrm{OH}) .{ }^{13} \mathrm{C}$ NMR $\left(100.6 \mathrm{MHz}, \mathrm{DMSO}-d_{6}\right) \delta: 102.07,110.42$, 114.23, 119.72, 130.70, 134.11, 144.24, 151.78, 153.96, 156.37, 162.01. FT-IR (ATR, cm ${ }^{-1}$ ): 1724, 1623, 1511, 1328, 1129811. Mp: $>312{ }^{\circ} \mathrm{C}$ dec. ESI-MS: $m / z$ (rel abund) calcd for $[\mathrm{M}-$ $\left.\mathrm{H}^{+}\right]$228.0415, measured 228.0408. $\Delta=0.7 \mathrm{mDa}$.

UGTs and Microsomes. Recombinant human UGTs 1A1, $1 \mathrm{~A} 3,1 \mathrm{~A} 6,1 \mathrm{~A} 7,1 \mathrm{~A} 8,1 \mathrm{~A} 9,1 \mathrm{~A} 10,2 \mathrm{~A} 1,2 \mathrm{~A} 2,2 \mathrm{~A} 3,2 \mathrm{~B} 4,2 \mathrm{~B} 10$, 
$2 \mathrm{~B} 7$, and $2 \mathrm{~B} 17$ were produced, as His-tagged proteins, in baculovirus-infected insect cells as previously described. ${ }^{37-39}$ The relative expression level of each of these recombinant UGTs was evaluated by immunodetection, using monoclonal antibody against the His-tag, as described elsewhere. ${ }^{40} \mathrm{~A}$ numeric value of 1.0 was given to the expression level of UGT1A8 and the relative expression level of each of the other UGTs was related to this value. Normalized activities were obtained by dividing the glucuronidation rate values by the relative expression level of the tested UGT. In addition, UGTs $1 \mathrm{~A} 4,2 \mathrm{~B} 10$, and $2 \mathrm{~B} 15$ were purchased from Corning Life Sciences (New York) and are marked, in Figure 5, with a " $\mathrm{C}$ " to indicate that they are commercial enzymes. The expression levels of the UGTs in the commercial samples could not be determined, so their protein concentration was used to calculate the reaction rate.

A commercial HLM pool (cat no:452210, BD Gentest, Bedford, MA) and human intestine microsomes (HIM) pool (lot. no 1110189, XenoTech, Kansas City, KS) were purchased. Pig liver samples were prepared from untreated female pigs that were used for practicing surgical procedures at the University of Kuopio (currently: University of Eastern Finland, Kuopio campus). Other animal liver microsomes were prepared as described previously. ${ }^{41}$ The Ethics Committee for Animal Experiments, University of Kuopio, approved these experiments.

Mutagenesis of UGT1A10. The UGT1A10 mutant 1A10$\mathrm{H} 210 \mathrm{M}$ was prepared according to the QuikChange methodology, using the cloned UGT1A10 in pFastBac ${ }^{42}$ as a template and the following two oligonucleotides:

1. 5'-ACTTTCAAGGAGAGAGTATGGAACATGATCGTGCACTTGGAGGACCATTT-3'

2. 5' - AAATGGTCCTCCAAGTGCACGATCATGTTCCATACTCTCTCCTTGAAAGT-3'

The entire coding sequence of UGT1A10 in the mutant clone was sequenced, and subsequently, recombinant baculovirus was prepared and used to express the mutant enzyme in baculovirus-infected SF9 insect cells.

Absorbance and Fluorescence Spectra of C3-Substituted 7-Coumarins. The absorbance spectra of $10 \mu \mathrm{M}$ coumarin derivatives at $100 \mathrm{mM}$ Tris $-\mathrm{HCl} \mathrm{pH} 7.4$ containing $10 \%$ dimethyl sulfoxide were measured using a Hitachi U-2000 Spectrophotometer (Tokyo, Japan). Excitation and emission fluorescence spectra of $0.1 \mu \mathrm{M}$ coumarin derivatives in $100 \mathrm{mM}$ Tris- $\mathrm{HCl}$ pH 7.4 were measured using a Shimadzu RF-5000 spectrophotofluorometer (Tokyo, Japan). The excitation spectra was from 200 to 420 at $460 \mathrm{~nm}$ emission and the emission spectra was from 400 to 600 at $390 \mathrm{~nm}$ excitation (data in Supplementary Table S1 and Figures S1 and S2). The effect of $\mathrm{pH}$ on fluorescence intensity was determined at 405 $\mathrm{nm}$ excitation and $460 \mathrm{~nm}$ emission, in the presence of $1.5 \%$ trichloroacetic acid, $100 \mathrm{mM}$ phosphate buffers at $\mathrm{pH} \mathrm{5,} \mathrm{6,} \mathrm{7,} \mathrm{8,}$ and 9, or 1.6 M glycine-NaOH pH 10.4.

Glucuronidation Reactions. The incubation mixtures for glucuronidation assays contained $100 \mathrm{mM}$ Tris- $\mathrm{HCl}$ buffer $\mathrm{pH}$ 7.4, $2.5 \mathrm{mM} \mathrm{MgCl}_{2}, 0.5 \mathrm{mM}$ UDPGA, recombinant UGT, or microsomes as the enzyme source and $0-15 \mu \mathrm{M}$ of the test aglycone substrate. When the incubation mixtures contained microsomes, alamethicin was used at a final concentration of $12.5 \mu \mathrm{g} / \mathrm{mL}$, but it was not included in the recombinant enzyme assays. ${ }^{43}$ In the first experiments three negative control samples were tested, namely (i) without the substrate 7hydroxycoumarin derivative, (ii) without the cofactor UDPGA, or (iii) without the enzyme source. In subsequent experiments, the control samples lacked the enzyme source since it gave the highest fluorescence background. Preliminary experiments were done under different conditions than most of the later assays, namely in $2.5 \mathrm{~mL}$ of $100 \mathrm{mM}$ phosphate buffer $\mathrm{pH}$ 7.4, containing $500 \mu \mathrm{g}$ pig liver microsomes, $1.0 \mu \mathrm{M}$ compound 6 and $0.5 \mathrm{mM}$ UDPGA, at room temperature. Fluorescence spectra (excitation $200-420 \mathrm{~nm}$; emission $400-600 \mathrm{~nm}$ ) or fluorescence decrease at $390 \mathrm{~nm}$ excitation and $460 \mathrm{~nm}$ emission, were measured in these preliminary experiments, using a Shimadzu RF-5000 spectrophotofluorometer.

Most of the glucuronidation assays were carried out in 96 multiwell plate format, and incubations were carried out in 100 $\mu \mathrm{L}$ and at $37^{\circ} \mathrm{C}$, in the presence of Tris- $\mathrm{HCl}$ buffer $\mathrm{pH} 7.4$, UDPGA, and the tested 7-hydroxycoumarin derivative, at the indicated concentrations. Fluorescence decline in the multiwell plate experiments was monitored every other minute, for 40 min, using an excitation filter at $405 \mathrm{~nm}$ and detection at 460 $\mathrm{nm}$, in a Victor2 1420 Multilabel counter (PerkinElmer, Life Sciences, Turku, Finland). The fluorescence values were transformed into molarity using the aglycone substrates for making the respective standard curves. Slopes of the substrate concentration decrease per minute were calculated using linear regression analysis, in which the linear part of the kinetic assay indicated the glucuronidation rate. Enzyme catalyzed glucuronidation rate was calculated by subtracting the blank value from the full reaction value. The intra-assay variability of the kinetic assays was $6 \%$ when compound 6 was used as the aglycone substrate. Kinetic analyses were also performed in the same 96 multiwell plates format, with excitation filter at $405 \mathrm{~nm}$ and detection at $460 \mathrm{~nm}$, using 6-8 different substrate concentrations per substrate and two different protein concentrations for both the wild-type and mutant UGT1A10. The higher concentrations, $13.5 \mathrm{mg} / \mathrm{L}$ for UGT1A10 and 12.0 $\mathrm{mg} / \mathrm{L}$ for the UGT1A10 mutant, were used when the substrates were HFC, compounds $\mathbf{4}$ and $\mathbf{6}$, whereas the lower protein concentrations, 6.75 and $6.0 \mathrm{mg} / \mathrm{L}$ for UGT1A10 and the mutant, respectively, were used when the substrates were compounds 1, 2, 3, and 5 .

In end-point determinations, the glucuronidation reactions were stopped by the addition of $150 \mu \mathrm{L} 1.6 \mathrm{M}$ glycine- $\mathrm{NaOH}$ buffer, $\mathrm{pH} 10.4$, followed by fluorescence measurements at 405 $\mathrm{nm}$ excitation and $460 \mathrm{~nm}$ emission. There was a good correlation between kinetic and end-point assays (data not shown).

HPLC-MS Analysis of 7-Hydroxy-3-triazolecoumarin Glucuronide. For further analysis of 7-hydroxy-3-triazolecoumarin glucuronide, $10 \mu \mathrm{M}$ of compound 6 were incubated in $100 \mu \mathrm{L}$ of $100 \mathrm{mM}$ Tris $-\mathrm{HCl} \mathrm{pH} 7.4$ buffer containing $5 \mathrm{mM}$ $\mathrm{MgCl}_{2}, 1 \mathrm{mM}$ UDPGA, and either 30-40 $\mu \mathrm{g}$ recombinant UGT, $30 \mu \mathrm{g}$ HLM, or $20 \mu \mathrm{g}$ HIM for $1 \mathrm{~h}$ at $37 \mathrm{C}$. The reactions were stopped by the addition of $300 \mu \mathrm{L}$ of methanol and centrifugation, and then the supernatant was divided into two. One part, $100 \mu \mathrm{L}$ supernatant, was mixed with $150 \mu \mathrm{L}$ of 1.6 $\mathrm{M}$ glycine- $\mathrm{NaOH} \mathrm{pH} 10.4$ and subjected to fluorescence measurements as described above for the 96-well plate. The other part, $250 \mu \mathrm{L}$ supernatant, was stored at $-20 \mathrm{C}$ until analysis by HPLC-MS.

An Agilent 1200 Series Rapid Resolution LC System (Agilent Technologies, Waldbronn, Germany) was used for the chromatographic separation, equipped with a reversed-phase C8 column (Brownlee Supra, $3 \mu \mathrm{m}, 50 \times 2.1 \mathrm{~mm}$, PerkinElmer). The mobile phases were (A) $0.1 \%$ aqueous 
formic acid and (B) acetonitrile. A linear gradient from $10 \%$ to $90 \% \mathrm{~B}$ in five min was applied, followed by one min isocratic elution with $90 \% \mathrm{~B}$ and column re-equilibration, yielding a total analysis time of nine min. The flow rate was $0.3 \mathrm{~mL} / \mathrm{min}$, injection volume $3 \mu \mathrm{L}$ and column oven temperature $30{ }^{\circ} \mathrm{C}$. For the MS detection, a Finnigan LTQ ion trap mass spectrometer (Thermo, San Jose, CA) was used in the positive electrospray (ESI) mode. A divert valve was used to direct eluent flow to the waste for $1 \mathrm{~min}$ at the beginning and at the end of the gradient run. The MS analysis was carried out using the following parameters: spray voltage $4 \mathrm{kV}$, sheath gas 30 (instrument units), aux gas 15, sweep gas 3, capillary temperature $250{ }^{\circ} \mathrm{C}$, capillary voltage $43 \mathrm{~V}$, tube lens $100 \mathrm{~V}$. The collision energy used for MS/MS was $30 \mathrm{~V}$. The acquired full scan MS range was $m / z 60-600$. Ions used for the detection of the aglycone and glucuronide conjugate were $\mathrm{m} / z$ $230[\mathrm{M}+\mathrm{H}]^{+}$and $m / z 406[\mathrm{M}+\mathrm{H}+176]^{+}$, respectively. Data was acquired and processed using Xcalibur software package.

\section{RESULTS}

Modeling UGT1A Enzymes. Template structures for homology modeling of the UGT enzymes of subfamily $1 \mathrm{~A}$ were selected based on sequence similarity using the blast option in Uniprot. Structures that contained both the sugarnucleotide cofactor and a small aglycone molecule were beneficial for the model, and therefore, structures (pdbcodes) $2 \mathrm{C} 1 \mathrm{Z} / \mathrm{X}, 2 \mathrm{O} 6 \mathrm{~L}, 3 \mathrm{HBF}$, and $3 \mathrm{WC} 4$ were selected. The conserved lipophilic region that spans the endoplasmic reticulum membrane and ends in the "cytoplasmic tail" were excluded from the model because the focus of the model construction was on the catalytic site and its surrounding area. In addition, other structures outside the catalytic site of the model, including loops and amino acid side chain conformations, were not optimized. Optimizing effords were considered detrimental for the quality of the models as the sequence similarity between the templates and the UGT sequences was very low. In other words, the models were not considered to be good enough for molecular dynamics simulations in order to evaluate binding energy or other kinetic parameters. On the other hand, an essential part of the model building was to predict binding of the 7-hydroxycoumarin derivatives so that glucuronidation will occur at the 7-hydroxyl group, and for this purpose the models were adequate.

The homology models were used to design novel and UGTselective fluorescent 7-hydroxycoumarin substrate molecules, whose fluorescence will decrease upon glucuronidation (Figure 1). Docking of the 7-hydroxycoumarin scaffolds (Figure 2A-C) into different UGT1A models yielded several possible conformations. One of them oriented the 7-hydroxy group toward the bound UDP-glucuronic acid (UDPGA) cofactor at the catalytic site, and simultaneously, the coumarin core was optimally placed into a nearby cavity in the catalytic site (Figure 2D). In our models, the coumarin scaffold could be stabilized through its C2-carbonyl oxygen, accepting a hydrogen bond from Q101 in UGT1A8 (Figure 2C), UGT1A9, and UGT1A10 (Figure 2A). Even stronger stabilizing interactions could be formed between the coumarin carbonyl at C2 and R102 of UGT1A6 (Figure 2C). On the other hand, D103 in UGT1A1 (Figure 2B), E104 in UGT1A3 and UGT1A4, or P101 in UGT1A7, are not capable of forming similar stabilizing hydrogen bond interactions at this site, suggesting that the coumarin core would not be an optimal substrate for these UGTs. Furthermore, R103 of UGT1A7, UGT1A8, and

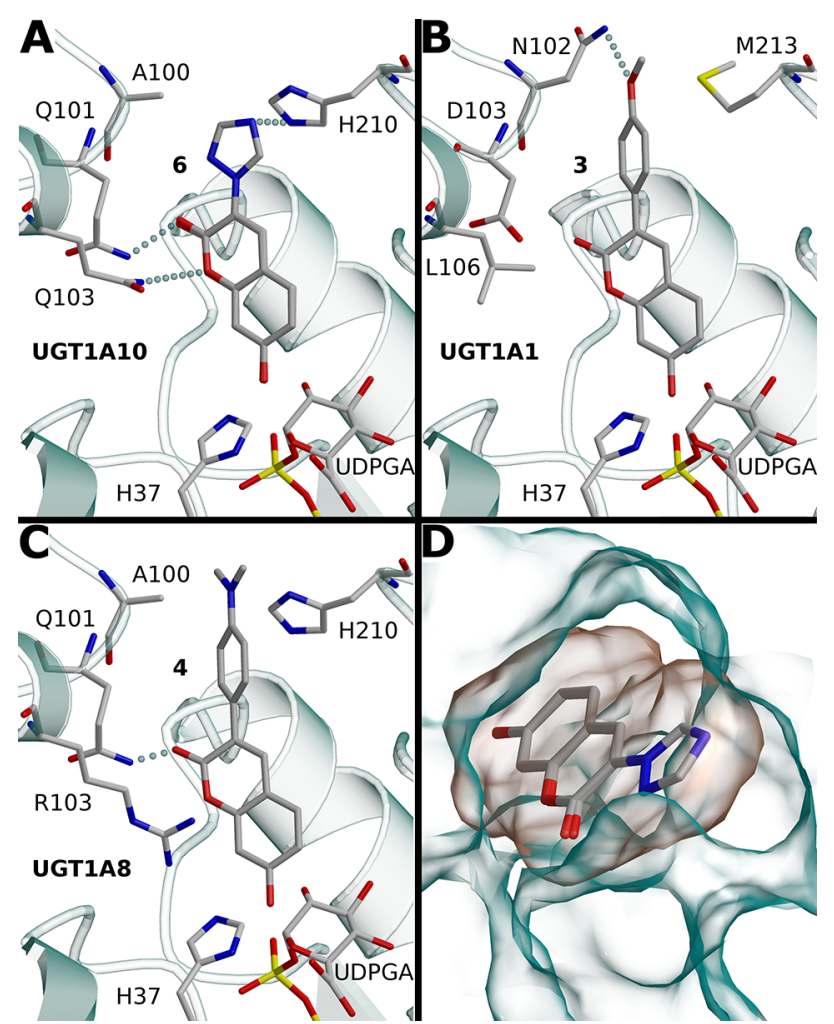

Figure 2. Docking of 7-hydroxycoumarin and its derivatives into the UGT1A10 model. (A) Molecular docking placed the 7-hydroxycoumarin with the 7-hydroxy facing the catalytic site formed by H37 and UDPGA, enabling the glucuronidation reaction and the subsequent decrease in fluorescence. (B) In UGT1A1, D103, and L106 are not capable of forming similar beneficial interactions with the coumarin core as the UGT1A10 model. Although N102 might be able to form beneficial interactions with certain compounds, the cavity might not be large enough for more sizable substitutions due to N102 and M213. (C) UGT1A8 has otherwise the same amino acid residues aligning the cavity as UGT1A10, except for R103. Due to its size, R103 might impair the binding of the coumarin core. (D) 6 fills the binding cavity (orange solvent accessible surface) of the UGT1A10 model (green solvent accessible surface). Docking suggests that the 7-hydroxycoumarin and 6 have a similar binding mode at their identical core. In addition, the $\mathrm{C} 3$ substituent of $\mathbf{6}$ fits tightly to the additional space at the outward facing end of the binding cavity.

UGT1A9, counteracted the stabilizing interactions and partially blocked the binding of the coumarin scaffold to these UGTs due to its size (Figure 2C). Unlike significantly bulkier R103 of UGT1A8 (Figure 2C), the Q103 of UGT1A10 at this site could donate a hydrogen bond to the oxygen at position 1 of the coumarin scaffold (Figure 2A).

Based on these homology models, there was an additional, but variable in size, free space available in the active site of each UGT1A enzyme, next to position 3 of the coumarin core. When combined with the 7-hydroxycoumarin docking site analyses (see above), this additional space was large enough in UGT1A1 and UGT1A10 to accommodate five- or sixmembered ring substituents (Figure 2D). In contrast, a bulkier phenylalanine (F212) is present in the UGT1A6 model at this position, clearly hindering binding of any 3-substituted 7hydroxycoumarins. The properties of this binding site were quite different also between UGT1A1 and UGT1A10. While UGT1A1 has a hydrophobic methionine (M213) facing this site (Figure 2B), UGT1A10 has a histidine at the 
<smiles>O=c1oc2cc(O)ccc2cc1-c1ccc(F)cc1</smiles>

Compound 1<smiles>O=c1oc2cc(O)ccc2cc1-c1ccc(O)cc1</smiles>

Compound 2<smiles>COc1ccc(-c2cc3ccc(O)cc3oc2=O)cc1</smiles>

Compound $\mathbf{3}$<smiles>CN(C)c1ccc(-c2cc3ccc(O)cc3oc2=O)cc1</smiles>

Compound 4<smiles>Cc1ccc(-c2cc3ccc(O)cc3oc2=O)cc1</smiles>

Compound 5<smiles>O=c1oc2cc(O)ccc2cc1-n1cncn1</smiles>

Compound 6<smiles>O=c1ccc2ccc(O)cc2o1</smiles>

\section{7-Hydroxycoumarin}<smiles>O=c1cc(C(F)(F)F)c2ccc(O)cc2o1</smiles>

HFC

Figure 3. Novel (1-6) and control 7-hydroxycoumarin and 7-hydroxy-4-trifluoromethylcoumarin (HCF) substrates of UGT1A enzymes in this study.
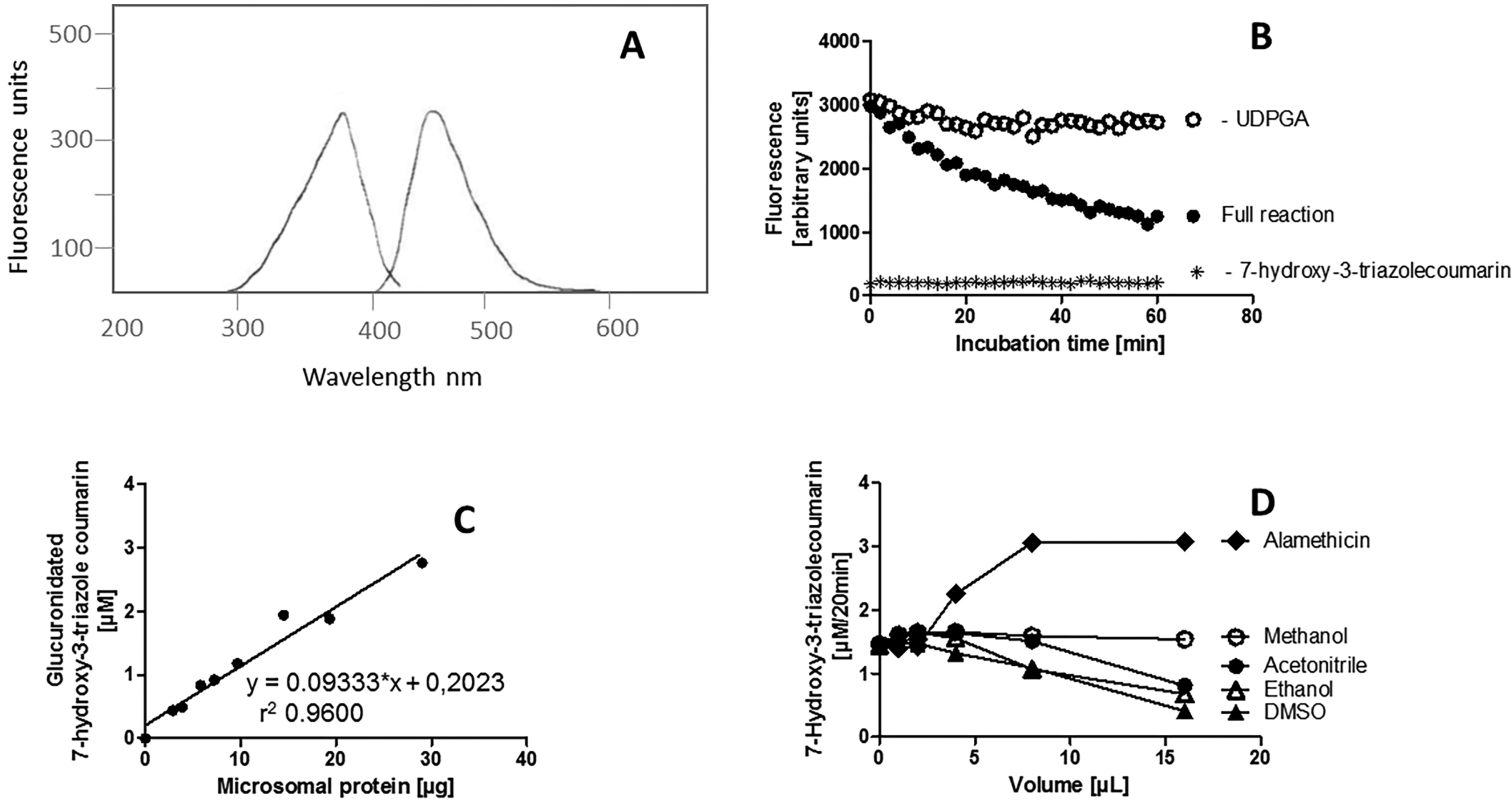

Figure 4. Decrease of 7-hydroxycoumarin fluorescence during glucuronidation. Excitation and emission fluorescence spectra of $0.1 \mu \mathrm{M} 7$-hydroxy-3triazolecoumarin at $100 \mathrm{mM}$ phosphate $\mathrm{pH} 7.4 \mathrm{buffer}$ (panel A); decrease in $10 \mu \mathrm{M}$ 7-hydroxy-3-triazolecoumarin fluorescence in the presence of 0.7 $\mathrm{mg} / \mathrm{mL}$ pig liver microsomal protein, $0.5 \mathrm{mM}$ UDPGA, $5 \mathrm{mM} \mathrm{MgCl}_{2}$, and $100 \mathrm{mM}$ Tris-HCL $\mathrm{pH} 7.4$ (panel B); effect of the amount of microsomal protein on the decrease in fluorescence (panel C); effect of solvents and alamethicin on the decrease in fluorescence (panel D). Corresponding results were obtained with other $\mathrm{C} 7$-substituted 7-hydroxycoumarin derivatives.

corresponding site (H210; Figure 2A). On the opposite side of this additional space, UGT1A10 has an alanine (A100), while UGT1A1 has an asparagine (N102) aligned to the same position. This may mean that in UGT1A10 there is enough space for rather large 3-substituted 7-hydroxycoumarins, whereas UGT1A1 would have problems accommodating larger subsitutions at this position of the 7-hydroxycoumarin scaffold. At the other end of the UGT1As "spectrum", UGT1A6 has a glutamic acid (E101) aligned at the same site, which would limit the cavity even further.

Based on docking of a virtual library into the UGT1A10 model, the most promising molecules were 7 -hydroxycoumarin 

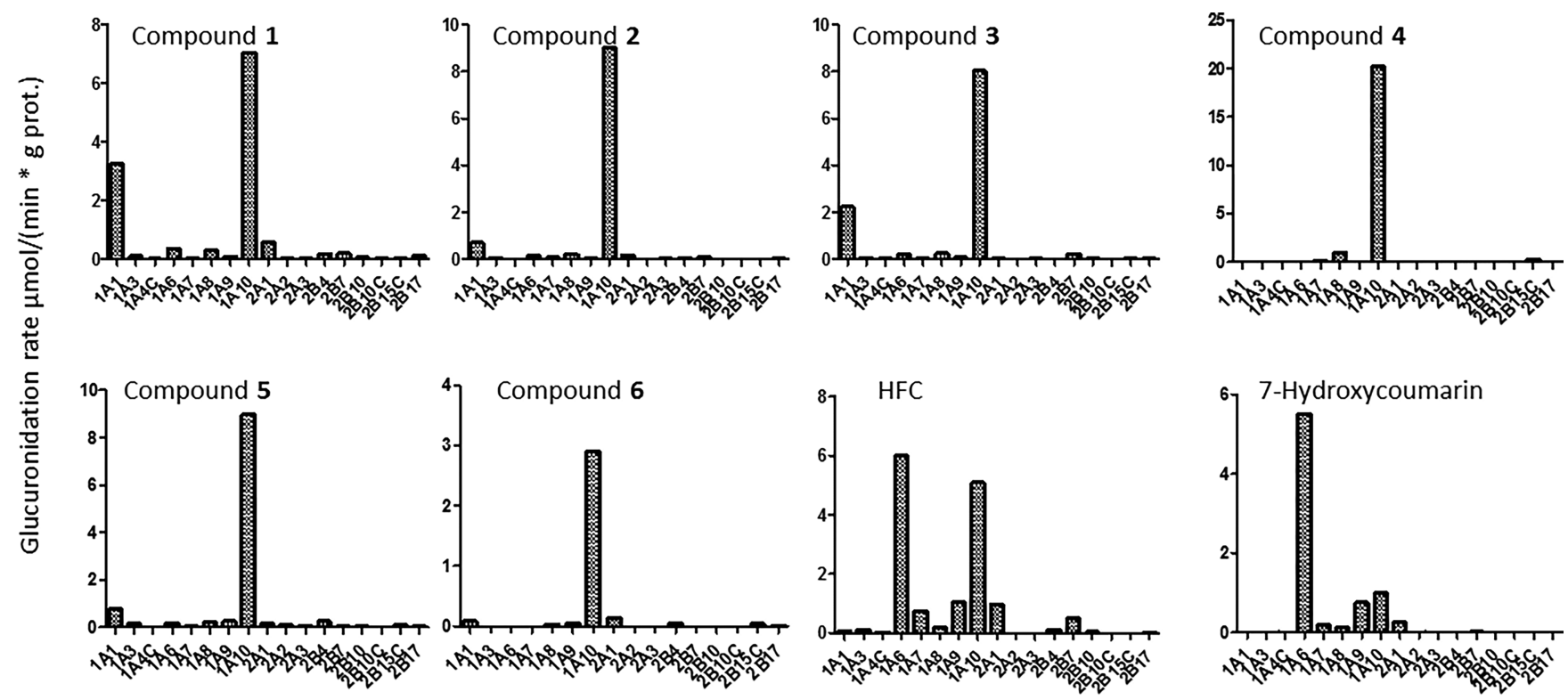

UGT enzyme
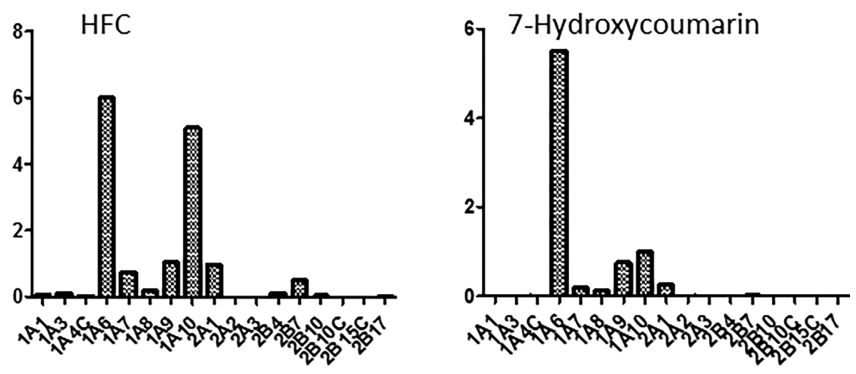

Figure 5. Glucuronidation of C3-substituted 7-hydroxycoumarins by human UGTs. Glucuronidation was determined at $10 \mu \mathrm{M}$ aglycone concentration.

derivatives with the following substituents at the $\mathrm{C} 3$ position: 4fluorophenyl (1), 4-hydroxyphenyl (2), 4-methoxyphenyl (3), 4-(dimethylamino)phenyl (4), 4-methylphenyl (5) or triazole (6). Among these, the triazole (6) derivative could be stabilized by $\mathrm{H} 210$ in UGT1A10, while the corresponding methionine in UGT1A1 (M213) would not be able to form hydrogen bonds with it. In contrast, the addition of a phenyl moiety to the C3position would allow binding by both UGT1A1 and UGT1A10, as the hydrophobic methionine in UGT1A1 is quite an ideal companion, while the histidine in UGT1A10 could change its conformation according to the donor functionality, as with triazole. Based on these observations and considerations, the six new coumarin derivatives were designed and synthesized (Figure 3: compounds 1-6). The selected compounds were made from inexpensive starting materials, producing 3substituted coumarins with 5- or 6-membered rings.

Glucuronidation of the 3-Substituted 7-Hydroxycoumarins. The absorbance and fluorescence spectra of compounds 1-6 were very similar showing, however, some differences in intensity as well as excitation and emission peaks among them (Figure 4A, Supplementary Figures 1 and 2, and Supplementary Table 1). The fluoresecence was $\mathrm{pH}$ dependent, emitting strongly in neutral and alkaline solutions.

In the first glucuronidation experiments, the fluorescence intensity of all of the C3-substituted 7-hydroxycoumarin derivatives, compounds 1-6, decreased when they were incubated in the presence of pig liver microsomes and UDPGA in a buffer containing $100 \mathrm{mM}$ Tris- $\mathrm{HCl} \mathrm{pH} 7.4$ and $5 \mathrm{mM} \mathrm{MgCl}_{2}$ (Figure $4 \mathrm{~B}$ ). No significant fluorescence decrease was observed in the negative controls, namely in the absence of either microsomes, a coumarin derivative such as $\mathbf{6}$, or UDPGA. The fluorescence changes were linearly dependent on the amount of microsomes (Figure 4C), indicating that the biosynthesis of $\mathrm{C} 3$ substituted 7-hydroxycoumarin derivatives to nonfluorescent glucuronide conjugates was catalyzed by one or more UDP-glucuronosyltransferase enzymes in the microsomes. The presence of alamethicin increased glucuronidation rates in this microsomal sample, whereas the addition of more than 5\% (v/v) dimethyl sulfoxide, acetonitrile, or ethanol decreased it (Figure 4D). An example for glucuronide formation under such incubation condition, using 6 as the substrate, is presented in Figure S3.

The above results with $\mathbf{6}$ and pig liver microsomes suggested that the glucuronidation rates of the new 7-hydroxycoumarin derivatives could be accurately determined under our standardized assay conditions, using different enzyme sources. Subsequently, the glucuronidation rates of all the new C3 substituted 7-hydroxycoumarin derivatives by nearly all the human UGTs, including enzymes that are not commercially available, were determined (Figure 5). For comparison and additional controls, the glucuronidation of 7-hydroxycoumarin and 4-(trifluoromethyl)-7-hydroxycoumarin (HFC), that carry no C3 substitution, by the recombinant enzymes were also measured (Figure 5).

The human UGTs screen revealed that all six newly synthesized C3 substituted 7-hydroxycoumarins were glucuronidated by UGT1A10 more rapidly than by other UGT forms. Furthermore, 2, 4, 5, and 6 were selective for UGT1A10, as other UGTs catalyzed their glucuronidation at very low rates. The remaining two new substrates, 1 and 3 , were glucuronidated, in addition to UGT1A10, also by UGT1A1, at rates of about $40 \%$ and $20 \%$, respectively, of the corresponding UGT1A10 rate (Figure 5). The glucuronidation profiles of the new derivatives differed significantly from the control substrates, 7-hydroxycoumarin and HFC, which were glucuronidated primarily by UGT1A6 (7-hydroxycoumarin), or UGT1A6 and UGT1A10 (HFC), as well as by few other UGTs at lower rates (Figure 5).

In addition to recombinant UGTs, the glucuronidation rates of all the new C3 7-hydroxycoumarin derivatives, along with 7hydroxycoumarin and HFC, were measured in human liver microsomes (HLM) and human intestinal microsomes (HIM). The results showed that all the new compounds were glucuronidated by HIM at higher rates than by HLM (Figure 6). Furthermore, 2, 4, and 6 were not glucuronidated by HLM at all, or only at very low rates, whereas 3 and 5 were 


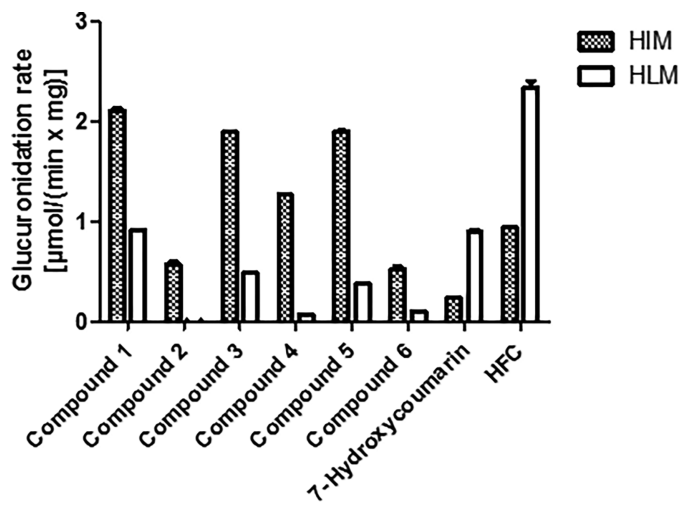

Figure 6. Glucuronidation of C3-substituted 7-hydroxycoumarins by human intestinal and hepatic microsomes. Glucuronidation was determined at $10 \mu \mathrm{M}$ aglycone concentration.

conjugated by HLM to about $20-25 \%$ of the rate exhibited by HIM. Compound 1 was glucuronidated by HLM at about $40 \%$ of the corresponding rate in HIM (Figure 6). Kinetics of compound $\mathbf{6}$ glucuronidation confirmed that glucuronidation is more specific in intestinal than hepatic microsomes, as its $K_{\mathrm{m}}$ value was $82(49-115) \mu \mathrm{M}$ and $V_{\max } 4.0(2.6-5.4) \mu \mathrm{mol} /$ (min* g prot) in human hepatic microsomes and its $K_{\mathrm{m}}$ value was $12(8.8-15) \mu \mathrm{M}$ and $V_{\max } 3.5(2.9-4.0) \mu \mathrm{mol} /(\min * \mathrm{~g}$ prot) in human intestinal microsomes. Adding albumin to the incubation mixture increased both $K_{\mathrm{m}}$ and $V_{\max }$ values in instestinal microsomes. In sharp contrast to glucuronidation of the new 7-hydroxycoumarin derivatives, the "parent compound" 7-hydroxycoumarin, as well as HFC, were glucuronidated to much higher rates by HLM than by HIM (Figure 6).
Effect of $\mathrm{H} 210$ to M210 Mutation on UGT1A10 Activity. The developed model, by being explicit about the role of certain key UGT1A10 residues in the binding of the designed 7-hydroxycoumarin derivatives, also allowed testing it by mutagenesis. Hence, we prepared mutant $1 \mathrm{~A} 10-\mathrm{H} 210 \mathrm{M}$, a mutant of UGT1A10 in which $\mathrm{H} 210$ was changed to methionine, the corresponding residue in UGT1A1. The mutant was expressed in insect cells, similarly to all the other recombinant UGTs that were used in this study, and its activity toward the new 7-hydroxycoumarin derivatives was tested. This was combined with kinetic analyses of the glucuronidation of these compounds by both UGT1A10 and UGT1A10-H201M, side by side (Figure 7 and Table 1). The results demonstrated clear effects of the mutation on the glucuronidation kinetics of most compounds. A decrease of $V_{\max }$ occurred in all but 2 and 6, in which the $K_{\mathrm{m}}$ values were considerably increased (Table $1)$. Changes in the $K_{\mathrm{m}}$ values of the other compounds were variable; however, an increase in the case of HFC, no change for $\mathbf{5}$, and a decrease in $\mathbf{1}, \mathbf{3}$, and 4 (Table 1).

\section{DISCUSSION}

In this study, we constructed predictive homology models for the human UGT1A enzymes in order to design selective substrates for them. The models indicated several key characteristics that differ among the active sites of individual UGT1A enzymes. These differences were exploited for the design and synthesis of six new 3-substituted 7-hydroxcoumarin derivatives. All the new compounds were good substrates for UGT1A10 and four of them, namely 2, 4, 5, and 6, were selective substrates for this UGT (Figure 5). Among the clear advantages of these new 7-hydroxcoumarin derivatives as UGT1A10 substrates are their extensive fluorescence and simple synthesis from low-cost starting materials that make

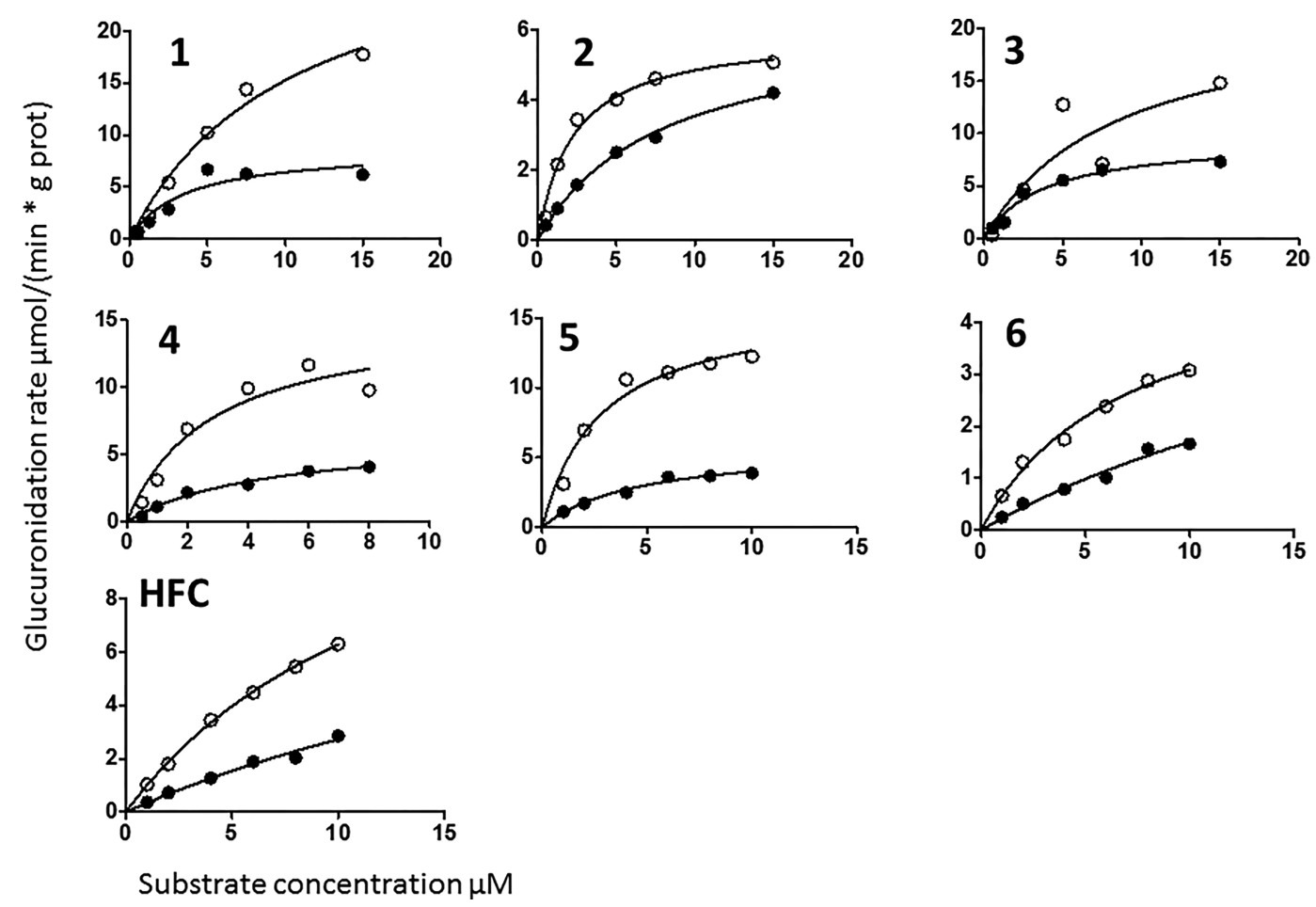

Figure 7. Michaelis-Menten kinetics of UGT1A10 (open circle) and UGT1A10 mutant (closed circle) catalyzed 7-hydroxyl glucuronidation for the 3-substituted 7-hydroxycoumarins (1-7 and HFC). The data are from one experiment, and the analyzed data are shown in Table 1. 


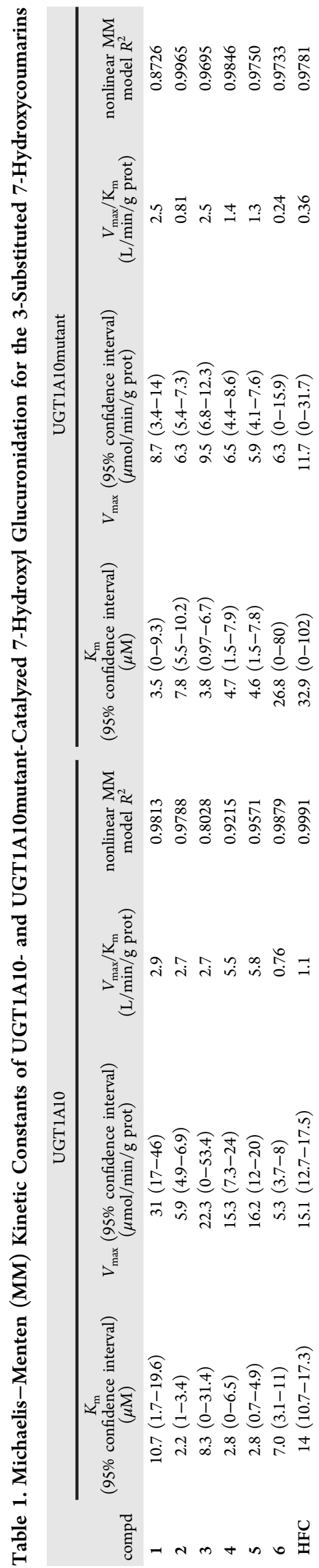

them suitable for quick and convenient activity measurements in a high-throughput format.

Currently, no high-resolution, or even low-resolution, structure of a full-length UGT is available from X-ray crystallography or cryo-electron microscopy. Although their 3D-model construction is challenging, homology models of UGT1A1, 1A3, 1A4, 1A5, 1A6, 1A7, 1A8, 1A9, and 1A10 were constructed in this study. These models suggested that the active site of UGT1A10 is sufficiently different from the other UGTs to enable design and synthesis of selective substrates for it.

We had two goals in designing these substrates: they should be selective for UGT1A10, and determination of their glucuronidation should be based on easily measurable fluorescence change during the assay. As a starting point, the 7-hydroxycoumarin scaffold was selected, since it is a common UGT substrate and its derivatives have intense fluorescence. ${ }^{44}$ In addition, 7-hydroxycoumarin and 7-hydroxy-4(trifluoromethyl)coumarin have both been shown to be glucuronidated by several different UGTs. ${ }^{25}$ The hydroxyl group of 7-hydroxycoumarin was oriented toward the UDPGA in the active site of the UGT1A10 model, indicating that there is space in the active site for an additional six or five ring substituent at position C3 of the 7-hydroxycoumarin scaffold (Figure 2). Thus, we synthesized six new UGT1A10 substrates, all of which were 7-hydroxycoumarin derivatives with various substituents at position $\mathrm{C} 3$ of the coumarin scaffold.

All of the new 7-hydroxycoumarin derivatives are highly fluorescent, and their fluorescence decreases upon enzymatic glucuronidation (see Figure 4 for an example with compound 6). A concern in these assays was nonlinearity of the fluorescence at substrate concentrations above $20 \mu \mathrm{M}$. However, fluorescence changes of these substrates were selective, sensitive and quantitative enough for measurements below this concentration limit, as the amount of UGT1A10 enzyme could be adjusted to yield linear glucuronidation rates.

The selectivities of the 7-hydroxycoumarin derivatives for UGT1A10 differed substantially. While some of them, such as 2, 4, and 6, were highly selective, others, like $\mathbf{1}$ and $\mathbf{3}$, were also glucuronidated by UGT1A1 at considerable rates (Figure 5). Previous studies have shown that fluorescent derivatives of $\mathrm{N}$ butyl-4-phenyl-1,8-naphthalimide are UGT1A1 selective substrates. ${ }^{45}$

Since UGT1A10 is an extrahepatic enzyme expressed at high levels in the intestine, ${ }^{11}$ the results obtained with recombinant UGTs could be tested with HLM and HIM. Although these microsomal preparations contain several different UGTs each, HLM lacks a functional UGT1A10 while HIM contains it. ${ }^{11}$ Indeed, the glucuronidation rates in HLM of $\mathbf{4}$ and $\mathbf{6}$, as well as 2 , were very low or below the detection limit. Glucuronidation of $\mathbf{1 , 3}$ and $\mathbf{5}$ took place in HLM at rates up to $40 \%$ of the rates in HIM (Figure 6). These results also suggest which of the new compounds would be most useful for studies on UGT1A10 activity in samples from human tissues that express or may express this enzyme. The current results point at 2, $\mathbf{4}$ and $\mathbf{6}$ as good candidates, 2 due to the lack of detectable activity in HLM, 4 based on the combination of high rate with high selectivity, and $\mathbf{6}$ due to its high selective fluorescence intensity (Figure 6 and Supplementary Figures S1 and S2). It may be added here that we recently reported that the commonly used commercial UGT1A10 has low activity. ${ }^{13}$ In this study we have used the UGT1A10-H preparation, not the commercial UGT1A10. Researches should not expect to get similar results 
to those reported here for UGT1A10 when working with the commonly used commercial UGT1A10. On the other hand, experiments with commercial HIM and HLM are expected to reproduce the current results.

It is interesting to understand why $\mathbf{6}$ has a remarkably lower (less than $30 \%)$ intrinsic glucuronidation clearance $\left(V_{\max } / \mathrm{K}_{\mathrm{m}}\right)$ by UGT1A10 than the other new 7-hydroxycoumarin derivatives, 1-5 (Table 1). Examination of the substituents at C3 suggests that 6 with a triazole derivative at C3 was glucuronidated less efficiently than derivatives containing hydrophobic or other types of hydrophilic substituents. The reason for this could be that the triazole causes stronger interactions than the other substituents in the active site of UGT1A10, resulting in slower release of the formed glucuronide.

The present modeling work indicates specific residues that are expected to lead to substrate selectivity of UGT1A10. We have tested one of the predicted residues, $\mathrm{H} 210$, by changing it to M210, the corresponding residue in UGT1A1, expressed the mutant UGT1A10-M210 and studied the glucuronidation kinetics of all the new compounds by both the wildtype (i.e., UGT1A10-H210) and mutant enzymes. The results revealed changes in the $\mathrm{K}_{\mathrm{m}}$ and/or $V_{\max }$ values of the glucuronidation kinetics of all the compounds, but with clear differences among them (Figure 7 and Table 1). Another unexpected observation was the effect of the mutation on HFC glucuronidation rate, which may suggest that the effect of the mutation is larger than expected by the model, or that substrate(s) binding by UGT1A10 (also) involves an induced fit mechanism.

In conclusion, in this study, 3D molecular models of the UGT1As were constructed and used for the design and synthesis of six new fluorescent UGT substrates. A new multiwell-based method that takes advantage of the fluorescence of the compounds and their fluorescence decrease upon glucuronidation was established to measure glucuronidation rates. Of the new compounds, 4-(dimethylamino)phenyl (4) and triazole (6) C3-substituted 7-hydroxycoumarins appeared to be the most selective substrates for UGT1A10, an important and often underestimated extrahepatic human UGT. It is concluded that the selectivity of the new coumarin derivatives for UGT1A10 depends on the chemical character of their substituent at $\mathrm{C} 3$. These new compounds should enable better, faster, and easier determination of UGT1A10 activity in tissues than was earlier possible. In addition, their further chemical modification could stimulate the development of new tools to explore the active site of different UGT enzymes.

\section{ASSOCIATED CONTENT}

\section{S Supporting Information}

The Supporting Information is available free of charge on the ACS Publications website at DOI: 10.1021/acs.molpharmaceut.7b00871.

Supplementary figures and tables (PDF)

\section{AUTHOR INFORMATION}

\section{Corresponding Authors}

*E-mail: risto.juvonen@uef.fi (in vitro).

*E-mail: olli.pentikainen@utu.fi (modeling and synthesis).

ORCID $\odot$

Risto O. Juvonen: 0000-0001-9240-7673

Moshe Finel: 0000-0003-1775-854X

Olli T. Pentikäinen: 0000-0001-7188-4016

\section{Author Contributions}

R.O.J, H.R., and O.T.P designed the study. S.R., S.N., and O.T.P. performed the modeling. S.K. and J.H. performed the synthesis of molecules. A.P. performed HPLC-MS analysis. R.O.J. performed the experimental measurements. M.F. provided the UGT enzymes and with J.T. prepared the mutant. All the authors contributed to writing of the manuscript.

Notes

The authors declare no competing financial interest.

\section{ACKNOWLEDGMENTS}

We thank Ms Hannele Jaatinen for excellent expertise in laboratory work. Finnish IT Centre for Science (CSC) is acknowledged for a generous computational grant (O.T.P.: jyy2516 and jyy2585). We thank Johanna Mosorin for her valuable contribution in the preparation of recombinant UGTs. Financial support of the academy of Finland (Grant No. 137589) and the Sigrid Juselius Foundation (Grant No. 4704583) is highly acknowledged.

\section{REFERENCES}

(1) Jones, C. R.; Hatley, O. J.; Ungell, A. L.; Hilgendorf, C.; Peters, S. A.; Rostami-Hodjegan, A. Gut Wall Metabolism. Application of PreClinical Models for the Prediction of Human Drug Absorption and First-Pass Elimination. AAPS J. 2016, 18 (3), 589-604.

(2) Gonzalez, F. J.; Coughtrie, M.; Tukey, R. H., Drug Metabolism. In Goodman \& Gilmans's The Pharmacological Basis of Therapeutics, 12th ed. ed.; Brunton, L. L., Chabner, B., Knollman, B., Eds.; McGrawHill: New York, 2011; pp 123-143.

(3) Mizuma, T. Intestinal glucuronidation metabolism may have a greater impact on oral bioavailability than hepatic glucuronidation metabolism in humans: A study with raloxifene, substrate for UGT1A1, 1A8, 1A9, and 1A10. Int. J. Pharm. 2009, 378 (1-2), 140-141.

(4) Ritter, J. K. Intestinal UGTs as potential modifiers of pharmacokinetics and biological responses to drugs and xenobiotics. Expert Opin. Drug Metab. Toxicol. 2007, 3 (1), 93-107.

(5) Wu, B. J.; Kulkarni, K.; Basu, S.; Zhang, S. X.; Hu, M. First-Pass Metabolism via UDP-Glucuronosyltransferase: a Barrier to Oral Bioavailability of Phenolics. J. Pharm. Sci. 2011, 100 (9), 3655-3681.

(6) Testa, B.; Kramer, S. D. The biochemistry of drug metabolism-an introduction: part 5. Metabolism and bioactivity. Chem. Biodiversity 2009, 6 (5), 591-684.

(7) Kaivosaari, S.; Finel, M.; Koskinen, M. N-glucuronidation of drugs and other xenobiotics by human and animal UDP-glucuronosyltransferases. Xenobiotica 2011, 41 (8), 652-69.

(8) Rowland, A.; Miners, J. O.; Mackenzie, P. I. The UDPglucuronosyltransferases: their role in drug metabolism and detoxification. Int. J. Biochem. Cell Biol. 2013, 45 (6), 1121-32.

(9) Court, M. H.; Zhang, X. L.; Ding, X. X.; Yee, K. K.; Hesse, L. M.; Finel, M. Quantitative distribution of mRNAs encoding the 19 human UDP-glucuronosyltransferase enzymes in 26 adult and 3 fetal tissues. Xenobiotica 2012, 42 (3), 266-277.

(10) Ohno, S.; Nakajin, S. Determination of mRNA Expression of Human UDP-Glucuronosyltransferases and Application for Localization in Various Human Tissues by Real-Time Reverse Transcriptase-Polymerase Chain Reaction. Drug Metab. Dispos. 2009, 37 (1), 32-40.

(11) Sato, Y.; Nagata, M.; Tetsuka, K.; Tamura, K.; Miyashita, A.; Kawamura, A.; Usui, T. Optimized Methods for Targeted PeptideBased Quantification of Human Uridine 5 '-Diphosphate-Glucuronosyltransferases in Biological Specimens Using Liquid Chromatography-Tandem Mass Spectrometry. Drug Metab. Dispos. 2014, 42 (5), 885-889.

(12) Hu, D. G.; Meech, R.; McKinnon, R. A.; Mackenzie, P. I. Transcriptional regulation of human UDP-glucuronosyltransferase genes. Drug Metab. Rev. 2014, 46 (4), 421-58. 
(13) Troberg, J.; Jarvinen, E.; Ge, G. B.; Yang, L.; Finel, M. UGT1A10 Is a High Activity and Important Extrahepatic Enzyme: Why Has Its Role in Intestinal Glucuronidation Been Frequently Underestimated? Mol. Pharmaceutics 2017, 14, 2875.

(14) Oda, S.; Kato, Y.; Hatakeyama, M.; Iwamura, A.; Fukami, T.; Kume, T.; Yokoi, T.; Nakajima, M. Evaluation of expression and glycosylation status of UGT1A10 in Supersomes and intestinal epithelial cells with a novel specific UGT1A10 monoclonal antibody. Drug Metab. Dispos. 2017, 45 (9), 1027-1034.

(15) Hoglund, C.; Sneitz, N.; Radominska-Pandya, A.; Laakonen, L.; Finel, M. Phenylalanine 93 of the human UGT1A10 plays a major role in the interactions of the enzyme with estrogens. Steroids 2011, 76 (13), 1465-1473.

(16) Kallionpaa, R. A.; Jarvinen, E.; Finel, M. Glucuronidation of estrone and 16alpha-hydroxyestrone by human UGT enzymes: The key roles of UGT1A10 and UGT2B7. J. Steroid Biochem. Mol. Biol. 2015, 154, 104-111.

(17) Itaaho, K.; Mackenzie, P. I.; Ikushiro, S.; Miners, J. O.; Finel, M. The configuration of the 17-hydroxy group variably influences the glucuronidation of beta-estradiol and epiestradiol by human UDPglucuronosyltransferases. Drug Metab. Dispos. 2008, 36 (11), 2307-15. (18) Sneitz, N.; Vahermo, M.; Mosorin, J.; Laakkonen, L.; Poirier, D.; Finel, M. Regiospecificity and stereospecificity of human UDPglucuronosyltransferases in the glucuronidation of estriol, 16-epiestriol, 17-epiestriol, and 13-epiestradiol. Drug Metab. Dispos. 2013, 41 (3), $582-91$.

(19) Itaaho, K.; Court, M. H.; Uutela, P.; Kostiainen, R.; Radominska-Pandya, A.; Finel, M. Dopamine is a low-affinity and high-specificity substrate for the human UDP-glucuronosyltransferase 1A10. Drug Metab. Dispos. 2009, 37 (4), 768-75.

(20) Raunio, H.; Kuusisto, M.; Juvonen, R. O.; Pentikainen, O. T. Modeling of interactions between xenobiotics and cytochrome P450 (CYP) enzymes. Front. Pharmacol. 2015, 6, 123.

(21) Kirchmair, J.; Goller, A. H.; Lang, D.; Kunze, J.; Testa, B.; Wilson, I. D.; Glen, R. C.; Schneider, G. Predicting drug metabolism: experiment and/or computation? Nat. Rev. Drug Discovery 2015, 14 (6), 387-404

(22) Dai, Z. R.; Feng, L.; Jin, Q.; Cheng, H.; Li, Y.; Ning, J.; Yu, Y.; Ge, G. B.; Cui, J. N.; Yang, L. A practical strategy to design and develop an isoform-specific fluorescent probe for a target enzyme: CYP1A1 as a case study. Chem. Sci. 2017, 8 (4), 2795-2803.

(23) Dai, Z. R.; Ge, G. B.; Feng, L.; Ning, J.; Hu, L. H.; Jin, Q.; Wang, D. D.; Lv, X.; Dou, T. Y.; Cui, J. N.; Yang, L. A Highly Selective Ratiometric Two-Photon Fluorescent Probe for Human Cytochrome P450 1A. J. Am. Chem. Soc. 2015, 137 (45), 14488-95.

(24) Miley, M. J.; Zielinska, A. K.; Keenan, J. E.; Bratton, S. M.; Radominska-Pandya, A.; Redinbo, M. R. Crystal structure of the cofactor-binding domain of the human phase II drug-metabolism enzyme UDP-glucuronosyltransferase 2B7. J. Mol. Biol. 2007, 369 (2), 498-511.

(25) Rahikainen, T.; Hakkinen, M. R.; Finel, M.; Pasanen, M.; Juvonen, R. O. A high throughput assay for the glucuronidation of $7-$ hydroxy-4-trifluoromethylcoumarin by recombinant human UDPglucuronosyltransferases and liver microsomes. Xenobiotica 2013, 43 (10), 853-61.

(26) Modolo, L. V.; Li, L.; Pan, H.; Blount, J. W.; Dixon, R. A.; Wang, X. Crystal structures of glycosyltransferase UGT78G1 reveal the molecular basis for glycosylation and deglycosylation of (iso)flavonoids. J. Mol. Biol. 2009, 392 (5), 1292-302.

(27) Hiromoto, T.; Honjo, E.; Tamada, T.; Noda, N.; Kazuma, K.; Suzuki, M.; Kuroki, R. Crystal structure of UDP-glucose:anthocyanidin 3-O-glucosyltransferase from Clitoria ternatea. J. Synchrotron Radiat. 2013, 20, 894-8.

(28) Offen, W.; Martinez-Fleites, C.; Yang, M.; Kiat-Lim, E.; Davis, B. G.; Tarling, C. A.; Ford, C. M.; Bowles, D. J.; Davies, G. J. Structure of a flavonoid glucosyltransferase reveals the basis for plant natural product modification. EMBO J. 2006, 25 (6), 1396-405.

(29) Lehtonen, J. V.; Still, D. J.; Rantanen, V. V.; Ekholm, J.; Bjorklund, D.; Iftikhar, Z.; Huhtala, M.; Repo, S.; Jussila, A.; Jaakkola,
J.; Pentikainen, O.; Nyronen, T.; Salminen, T.; Gyllenberg, M.; Johnson, M. S. BODIL: a molecular modeling environment for structure-function analysis and drug design. J. Comput.-Aided Mol. Des. 2004, 18 (6), 401-19.

(30) Johnson, M. S.; Overington, J. P. A structural basis for sequence comparisons. An evaluation of scoring methodologies. J. Mol. Biol. 1993, 233 (4), 716-38.

(31) Sali, A.; Blundell, T. L. Comparative protein modelling by satisfaction of spatial restraints. J. Mol. Biol. 1993, 234 (3), 779-815.

(32) Niinivehmas, S. P.; Salokas, K.; Latti, S.; Raunio, H.; Pentikainen, O. T. Ultrafast protein structure-based virtual screening with Panther. J. Comput.-Aided Mol. Des. 2015, 29 (10), 989-1006.

(33) Korb, O.; Stutzle, T.; Exner, T. E. Empirical scoring functions for advanced protein-ligand docking with PLANTS. J. Chem. Inf. Model. 2009, 49 (1), 84-96.

(34) Niinivehmas, S. P.; Manivannan, E.; Rauhamaki, S.; Huuskonen, J.; Pentikainen, O. T. Identification of estrogen receptor alpha ligands with virtual screening techniques. J. Mol. Graphics Modell. 2016, 64, 30-9.

(35) Kirkiacharian, S.; Lormier, A. T.; Resche-Rigon, M.; Bouchoux, F.; Cerede, E. [Synthesis and binding affinity of 3-aryl-7hydroxycoumarins to human alpha and beta estrogen receptors]. Ann. Pharm. Fr. 2003, 61 (1), 51-6.

(36) Buuhoi, N. P.; Ekert, B.; Royer, R. Bz-Hydroxylated-3-ArylCoumarins and 3,4-Diaryl-Coumarins. J. Org. Chem. 1954, 19 (9), $1548-1552$

(37) Kurkela, M.; Garcia-Horsman, J. A.; Luukkanen, L.; Morsky, S.; Taskinen, J.; Baumann, M.; Kostiainen, R.; Hirvonen, J.; Finel, M. Expression and characterization of recombinant human UDPglucuronosyltransferases (UGTs). UGT1A9 is more resistant to detergent inhibition than other UGTs and was purified as an active dimeric enzyme. J. Biol. Chem. 2003, 278 (6), 3536-44.

(38) Kuuranne, T.; Aitio, O.; Vahermo, M.; Elovaara, E.; Kostiainen, R. Enzyme-assisted synthesis and structure characterization of glucuronide conjugates of methyltestosterone (17 alpha-methylandrost-4-en-17 beta-ol-3-one) and nandrolone (estr-4-en-17 beta-ol-3one) metabolites. Bioconjugate Chem. 2002, 13 (2), 194-9.

(39) Sneitz, N.; Court, M. H.; Zhang, X.; Laajanen, K.; Yee, K. K.; Dalton, P.; Ding, X.; Finel, M. Human UDP-glucuronosyltransferase UGT2A2: cDNA construction, expression, and functional characterization in comparison with UGT2A1 and UGT2A3. Pharmacogenet. Genomics 2009, 19 (12), 923-34.

(40) Kurkela, M.; Patana, A. S.; Mackenzie, P. I.; Court, M. H.; Tate, C. G.; Hirvonen, J.; Goldman, A.; Finel, M. Interactions with other human UDP-glucuronosyltransferases attenuate the consequences of the Y485D mutation on the activity and substrate affinity of UGT1A6. Pharmacogenet. Genomics 2007, 17 (2), 115-26.

(41) Lang, M. A.; Gielen, J. E.; Nebert, D. W. Genetic evidence for many unique liver microsomal P-450-mediated monooxygenase activities in heterogeneic stock mice. J. Biol. Chem. 1981, 256 (23), 12068-75.

(42) Kuuranne, T.; Kurkela, M.; Thevis, M.; Schanzer, W.; Finel, M.; Kostiainen, R. Glucuronidation of anabolic androgenic steroids by recombinant human UDP-glucuronosyltransferases. Drug Metab. Dispos. 2003, 31 (9), 1117-24.

(43) Zhang, H.; Tolonen, A.; Rousu, T.; Hirvonen, J.; Finel, M. Effects of cell differentiation and assay conditions on the UDPglucuronosyltransferase activity in Caco-2 cells. Drug Metab. Dispos. 2011, 39 (3), 456-64.

(44) Lavis, L. D.; Raines, R. T. Bright building blocks for chemical biology. ACS Chem. Biol. 2014, 9 (4), 855-66.

(45) Lv, X.; Feng, L.; Ai, C. Z.; Hou, J.; Wang, P.; Zou, L. W.; Cheng, J.; Ge, G. B.; Cui, J. N.; Yang, L. A Practical and High-Affinity Fluorescent Probe for Uridine Diphosphate Glucuronosyltransferase 1A1: A Good Surrogate for Bilirubin. J. Med. Chem. 2017, 60 (23), 9664-9675. 